\title{
Awareness of Payment Reform: a Survey of Patients, Staff, and Providers in Safety Net Primary Care Clinics
}

\author{
Katherine Diaz Vickery, MD, MSc' (D), Becky R. Ford, PhD², Eileen M. Harwood, PhD ${ }^{3}$, \\ Katherine F. Guthrie, $M D^{4}$, and Mark Linzer, $M D^{1}$
}

'Hennepin Healthcare, Minneapolis, MN, USA; ${ }^{2}$ Hennepin Healthcare Research Institute, Minneapolis, MN, USA; ${ }^{3}$ School of Public Health, University of Minnesota, Minneapolis, MN, USA; ${ }^{4}$ Allina Health, United Family Medicine, Saint Paul, MN, USA.

$J$ Gen Intern Med 35(5):1597-9

DOI: $10.1007 / \mathrm{s} 11606-019-05451-3$

(c) Society of General Internal Medicine 2019

\section{INTRODUCTION}

Payment reform has been increasing in the U.S. health care system in recent years. Reforms move away from fee-forservice toward value-based payments, or compensation perpatient tied to care quality goals. ${ }^{1}$ Value-based payment is hypothesized to achieve the quadruple aim-improved care quality at lower costs with more satisfied patients and providers. $^{2}$

Value-based payment presents both opportunities and challenges for health care clinics that see majority low-income patients (i.e., the safety net). While offering flexibility to invest in services to address patients' social needs, ${ }^{3}$ it may discourage care for costly populations. ${ }^{4}$ Although evidence suggests costsavings of value-based payment models for low-income, complex populations, ${ }^{5}$ the study of payment reform has focused on regional impact and rarely details mechanisms of change at the clinic level. Previous measurement of engagement within value-based programs has depended on secondhand reports from leaders, ${ }^{6}$ not providers or patients, and has not focused on the safety net. Engagement of safety net clinic stakeholders in delivery system transformation is essential for achieving quadruple aim goals and avoiding unintended consequences, but stakeholders must first be aware of payment reform and its connection to changes at the clinic level.

To improve understanding of the impact of payment reform on safety net primary care delivery, we evaluated the awareness of patients, staff, and providers of ongoing payment reforms and their perceptions of changes at their clinics in

Prior presentations: We presented this data at the Minnesota Academy of Family Physicians Research and Innovation day on March 2, 2019.

Received July 12, 2019

Accepted September 27, 2019

Published online October 17, 2019 one urban region with early adoption of Medicaid value-based payment models.

\section{METHODS}

Institutional Review Boards at Allina Health, Hennepin Healthcare, and the University of Minnesota approved this study. First, we conducted interviews with stakeholders to design novel survey questions about patient, staff, and provider awareness of payment reform. We conducted crosssectional surveys of stakeholders at three safety net primary care clinics at two time points 11 months apart (2017 and 2018).

We recruited providers and staff at clinic-wide meetings and left paper surveys for those absent. We recruited convenience samples of patients in clinic waiting rooms.

We used Stata 15.1 to analyze data and followed the Strengthening of Reporting Observational Studies in Epidemiology (STROBE) guidelines. We conducted chi-squared tests to compare awareness of payment reform among stakeholder groups.

\section{RESULTS}

In total, 218 of 388 patients completed surveys (56\%), and 302 of 413 staff/providers (73\%). Ineligible non-English-speaking patients lowered our response rate. We found no significant differences between responses over time, so we collapsed the data removing respondents who took the survey in both years. Our final sample had 214 patients, 136 staff, and 116 providers (Table 1).

Awareness of payment reform varied significantly between stakeholder groups $\left(\chi^{2}=95.07, p<.001\right)$ (Fig. 1). Only $27 \%$ of patients were aware of payment reform, lower than the expected value under the null hypothesis. Staff and providers had greater than expected awareness of reform with $64 \%$ and $81 \%$ aware, respectively. 
Table 1 Characteristics of Safety Net Clinic Stakeholders Surveyed

\begin{tabular}{llll}
\hline \hline Characteristic & $\begin{array}{l}\text { Staff } \\
(\boldsymbol{n}=\mathbf{1 3 1})\end{array}$ & $\begin{array}{l}\text { Providers } \\
(\boldsymbol{n}=\mathbf{1 1 6})\end{array}$ \\
\hline Gender (no. (\%)) & & $\begin{array}{l}\text { Patients } \\
(\boldsymbol{n}=\mathbf{2 1 4})\end{array}$ \\
$\quad$ Male & $25(19.4)$ & $45(39.5)$ & $73(34.1)$ \\
Female & $104(80.6)$ & $69(59.5)$ & $127(59.4)$ \\
Other & $0(0.0)$ & $0(0.0)$ & $1(0.5)$ \\
Missing & $2(1.5)$ & $2(1.7)$ & $13(6.1)$ \\
Race* (no. (\%)) & $16(12.2)$ & $9(7.8)$ & $78(36.5)$ \\
Black/African American & $83(63.3)$ & $88(75.9)$ & $14(12.1)$ \\
White/Caucasian & $11(8.4)$ & $0(0.0)$ & $2(0.9)$ \\
Asian/Asian American & $3(2.2)$ & $6(5.2)$ & $9(4.2)$ \\
Native American/Alaskan Native & $12(9.2)$ & $3(2.6)$ & $17(7.9)$ \\
Other & $11(8.4)$ & $4(3.6)$ & $20(9.4)$ \\
Missing & $18(15.5)$ & $107(96.4)$ & $20(10.8)$ \\
Ethnicity (no. (\%)) & $98(84.5)$ & $3(4.3)$ & $166(89.3)$ \\
Latino/Hispanic & $15(11.5)$ & $39.2(14.5)$ & $28(13.1)$ \\
Not Latino/Hispanic & $40.8(15.6)$ & $47.7(18.2)$ \\
Missing & &
\end{tabular}

*Totals are greater than $n$ because respondents were allowed to classify themselves in more than one category.

Among respondents aware of reforms, perceptions differed about the extent to which reforms caused changes to their care/ work (Fig. $1 ; \chi^{2}=14.03, p=.03$ ). Twenty-eight percent of aware patients and $30 \%$ of aware providers perceived changes in their care/work due to reforms. However, $45 \%$ of aware staff attributed changes in their work to payment reform.

\section{DISCUSSION}

This study revealed stark differences in awareness of payment reform among stakeholders at safety net primary care clinics. Patients had particularly low awareness of reforms.
Importantly, even among stakeholders aware of reforms, approximately one in three felt reforms changed their care/work experience. This research complements the large body of evidence on the regional impacts of value-based payments models and harkens back to past problems with capitated payments under health maintenance organizations.

Limitations of this work include a small sample in one metropolitan area and use of a novel survey. In addition, we cannot determine the cause of low perceptions of care/work changes due to payment reform.

The results of this study indicate a need to include clinic stakeholders in the development and implementation of value-

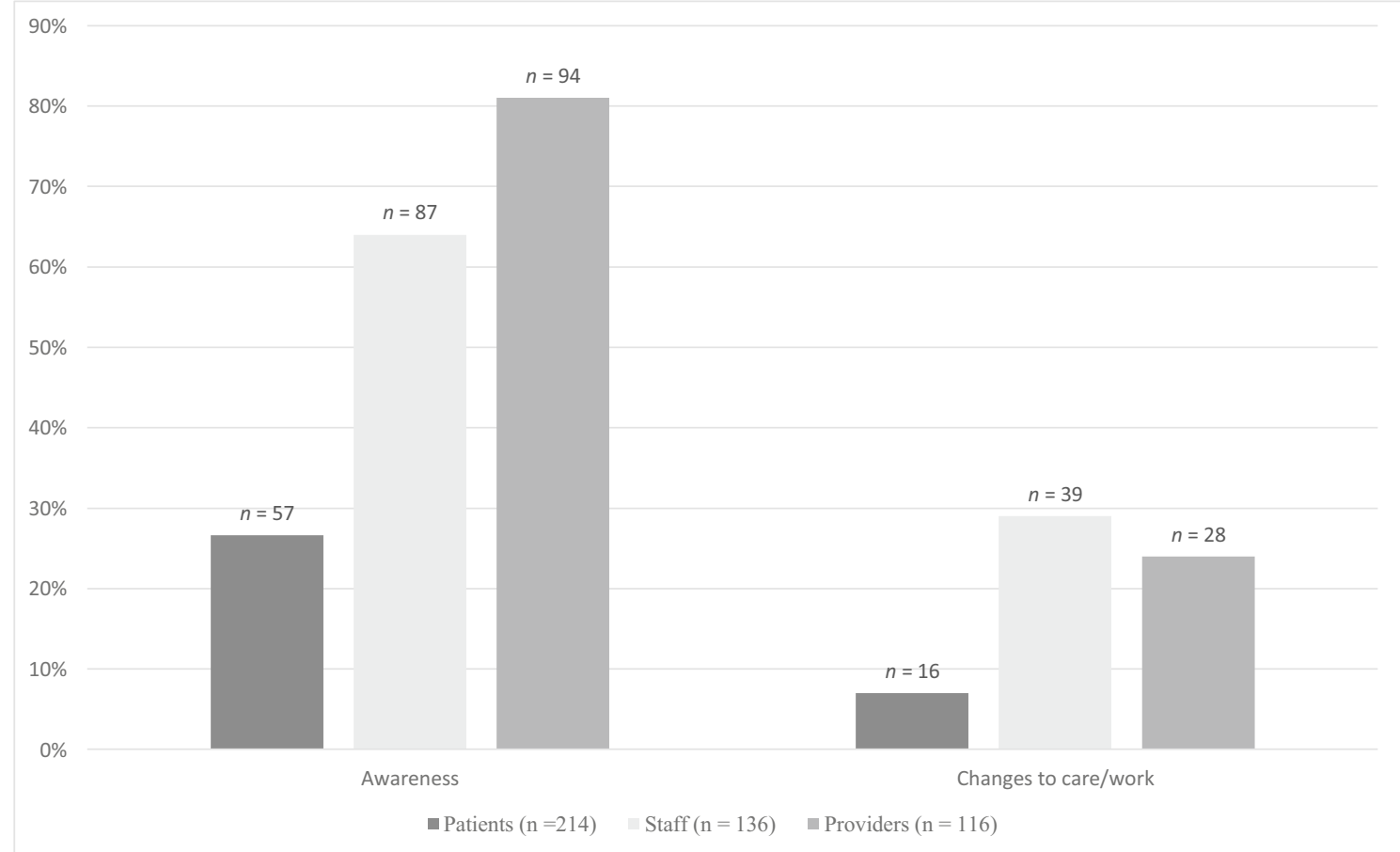

Figure 1 Proportion of clinic stakeholders aware of ongoing payment reforms and proportion of aware stakeholders perceiving connection of clinic change with reforms. 
based payment models. Inclusion of frontline patients, staff, and providers may play a key role in ensuring value-based payment reforms achieve real and meaningful changes to care delivery and quality.

Acknowledgments: We would like to acknowledge Melissa M. Adkins for help with data collection, management, and submission.

Corresponding Author: Katherine Diaz Vickery, MD, MSc; Hennepin Healthcare, Minneapolis, MN, USA (e-mail: Katherine.Vickery@hcmed. org).

Funding Information This paper was supported by a grant (no. 73615) from the Robert Wood Johnson Foundation.

\section{Compliance with Ethical Standards:}

Conflict of Interest: Dr. Linzer works with AMA, Institute for Healthcare Improvement and the American College of Physicians, on clinician work life improvements. Dr. Guthrie reports that her husband owns stock in Merck and Express Scripts. The other authors report no conflicts.

\section{REFERENCES}

1. Fisher ES, Staiger Do, Bynum JPW, Gottlieb DJ. Creating Accountable Care Organizations: The Extended Hospital Medical Staff. Health Aff (Millwood). 2007;26(1):w44-w57. https://doi.org/10.1377/hlthaff.26.1.w44

2. Bodenheimer T, Sinsky C. From Triple to Quadruple Aim: Care of the Patient Requires Care of the Provider. Ann Fam Med. 2014;12(6):573-576. https://doi.org/10.1370/afm.1713

3. Lewis VA, Larson BK, McClurg AB, Boswell RG, Fisher ES. The Promise And Peril Of Accountable Care For Vulnerable Populations: A Framework For Overcoming Obstacles. Health Aff (Millwood). 2012;31(8):1777-1785. https://doi.org/10.1377/hlthaff.2012.0490

4. Pollack CE. Accountable Care Organizations and Health Care Disparities. JAMA. 2011;305(16):1706. https://doi.org/10.1001/jama.2011.533

5. McConnell KJ, Renfro S, Lindrooth RC, Cohen DJ, Wallace NT, Chernew ME. Oregon's Medicaid Reform And Transition To Global Budgets Were Associated With Reductions In Expenditures. Health Aff (Millwood). 2017;36(3):451-459. https://doi.org/10.1377/hlthaff.2016.1298

6. Shortell SM, Sehgal NJ, Bibi S, et al. An Early Assessment of Accountable Care Organizations' Efforts to Engage Patients and Their Families. Med Care Res Rev. 2015;72(5):580-604. https://doi.org/10. $1177 / 1077558715588874$

Publisher's Note Springer Nature remains neutral with regard to jurisdictional claims in published maps and institutional affiliations. 